\section{Trypanosoma cruzi I: único tipo del parásito tripanosómico circulante en Panamá}

La enfermedad de Chagas o tripanosomiasis, se caracteriza por una gran diversidad en su actividad patogénica y en las manifestaciones clínicas que produce en diferentes áreas geográficas. Diversos autores han atribuido esta heterogeneidad a la variabilidad genética del trematodo Trypanosoma cruzi, agente causal de esta enfermedad, y a las variaciones del sistema inmunitario del organismo hospedero. En la zona norte de América del Sur y en América Central, el T. cruzi I es el tipo predominante - y en ocasiones exclusivo- de este parásito. En Panamá, la fuente principal de infección en humanos son los triatominos no domésticos, infectados de forma natural durante su ciclo de vida enzoótico en vectores selváticos y algunas especies de mamíferos silvestres. Estos triatominos infectados llegan a las casas atraídos por la luz y las personas.

Para la caracterización de las diferentes cepas de $T$. cruzi se han empleado diversos métodos basados en técnicas de biología molecular. De ellos, el análisis de las mutaciones de algunos genes mediante la secuenciación de fragmentos de ADN amplificados con la reacción en cadena de la polimerasa (RCP) ha demostrado ventajas y una mayor especificidad en la discriminación de los diferentes tipos de parásitos.

Precisamente mediante esta metodología, los autores de este trabajo han buscado confirmar el predominio de la cepa T. cruzi I en Panamá, para lo que se amplificó un fragmento de la región no traducida 3' del gen de la calmodulina. Este gen ha servido para confirmar estructuras poblacionales descritas previamente mediante el análisis del gen miniexon, ya que algunas mutaciones en la secuencia nucleotídica del extremo 3' de este gen son específicas para los diferentes aislamientos de T. cruzi I, II y el zimodemo III.

Para este estudio se emplearon muestras de 24 aislamientos de personas residentes en las principales zonas endémicas de tripanosomiasis de la región central de Panamá $(n=14)$ y de triatominos infectados en zonas silvestres en el distrito de Boquete, en la parte occidental del país $(n=10)$. Las muestras se cultivaron durante 7 días para obtener $10^{8}$ parásitos, de los cuales se extrajo y purificó el ADN, se amplificó la región $3^{\prime}$ del gen de la calmodulina mediante la RCP y se alinearon las secuencias directas de los productos de la amplificación mediante diferentes programas informáticos. Como controles se utilizaron cepas de los diversos grupos de parásitos caracterizados con anterioridad (T. cruzi I, II y zimodemo III).

El alineamiento de las secuencias parciales demostró que todos los parásitos aislados correspondían al tipo T. cruzi I. En todas las cepas de control se obtuvieron las mutaciones específicas, lo que confirmó el correcto funcionamiento de las técnicas empleadas.

A pesar de que las secuencias analizadas se obtuvieron mediante técnicas de amplificación molecular y de que el genoma de T. cruzi contiene cerca de diez copias del gen de la calmodulina, las mutaciones puntuales observadas en las secuencias obtenidas -además de los principales marcadores de deleción e inserción- demostraron el polimorfismo presente dentro de esta especie.

En conclusión, a partir de la secuencia parcial de la región no traducida del extremo 3' del gen de la calmodulina se pudo confirmar que en Panamá circula solamente la cepa $T$. cruzi I, tanto en las personas como en los animales hospederos. Estos resultados confirman la estructura poblacional descrita ya mediante otros marcadores moleculares, como los obtenidos a partir del análisis molecular del gen miniexon. (Brandao A, Samudio F, Fernandes O, Calzada JE, Sousa OE. Genotyping of Panamanian Trypanosoma cruzi stocks using the calmodulin 3'UTR polymorphisms. Parasitol Res. 2008;102:523-6.) 